\title{
Effect of pressure on the integrity of the duct-acinar system of the pancreas
}

\author{
R. C. PIROLA ${ }^{1}$ AND A. E. DAVIS \\ From the Department of Medicine, Prince Henry Hospital, Sydney, Australia
}

SUMMARY India ink introduced into the pancreatic ducts of the cat can escape into the interstitium at pressures below the maximum secretory pressure of the pancreas. The ink appears to leave through clefts between the acinar cells.

It is commonly held that a major factor in the production of pancreatitis is the development of a high pressure in the pancreatic ducts leading to the escape of pancreatic secretions into the interstitial tissues (Bockus, 1965; Snodgrass and Inglefinger, 1966). However, there is little information regarding the pressures at which this might occur. To be of clinical significance, it should take place at pressures below the maximum secretory pressure of the pancreas. The following study was undertaken to investigate this hypothesis.

\section{Materials and Methods}

Twenty fasting adult cats were anaesthetised with intravenous pentobarbitone. In three cats, a cannula was inserted into the main pancreatic duct with its tip facing the gland. The pressure in the cannula was recorded continuously by a strain-gauge manometer. After 30 minutes of observation, secretin and pancreozymin, each in a dose of $3 \mathrm{U} / \mathrm{kg}$ body weight, were given intravenously and the pressures recorded for a further 30 minutes.

In each of the remaining 17 cats, two cannulae were introduced into the pancreatic duct system.

${ }^{1}$ Present address: Medical Unit, Royal Free Hospital, Gray's Inn Road, London WC1
One was placed in the extraglandular portion of the main pancreatic duct with its open end facing the gland and one was placed in the duct of the ventral lobe with its tip facing towards the sphincter of Oddi (Fig. 1).

Before insertion each cannula was filled with filtered, sterile India ink. Each cannula was connected by means of a three-way stopcock to a strain-gauge monometer and to a suspended bottle containing India ink. One of the cannulae was temporarily disconnected from its manometer while ink was run in through the other cannula at a pressure not exceeding $20 \mathrm{~mm} \mathrm{Hg}$. Thus the pancreatic duct system between the two cannulae was filled with ink. The pressure in both cannulae was then raised to a known level for 15 minutes. This was $20 \mathrm{~mm} \mathrm{Hg}$ in six cats, $30 \mathrm{~mm} \mathrm{Hg}$ in five cats, and $40 \mathrm{~mm} \mathrm{Hg}$ in six cats. During the experiment, the duodenum was opened so that the accessory duct, if present, could be detected. This was seen in five of the seventeen cats and its orifice was clamped with a pair of artery forceps. At the end of each test the pancreatic cannulae were ligated, taking care not to raise the pressure in the ducts, and the pancreas was excised and placed in formalin. After the specimen had been photographed, two blocks were taken for light microscopy from each of the two main lobes of the pancreas from points $2 \mathrm{~cm}$ on either side of the sphincter of Oddi. 


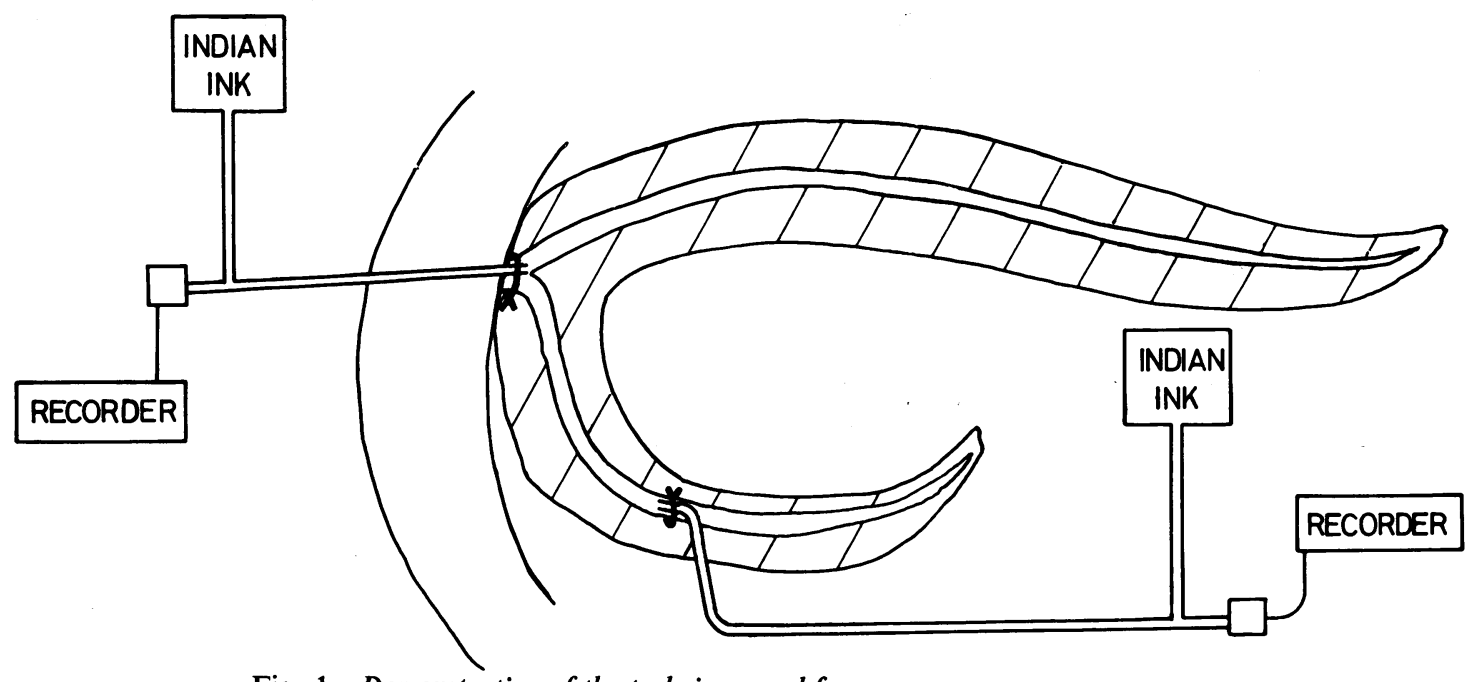

Fig. 1 Demonstration of the technique used for infusing India ink into the pancreas of the cat.

Photographs of the specimens were then viewed blindly by two observers who independently classified them into three arbitrary grades according to the degree of change in colour. Sections for microscopy were stained with neutral red and were similarly graded according to the degree of estravasation of ink particles outside the ducts and acini.

\section{Results}

In the three cats in which the secretory pressure during stimulation was measured, pressures in the control period were initially 12 to $15 \mathrm{~mm} \mathrm{Hg}$, falling gradually to 5 to $10 \mathrm{~mm} \mathrm{Hg}$. Stimulation was followed by a rise to peaks of 45,47 , and $48 \mathrm{~mm} \mathrm{Hg}$ within 10 minutes, followed by a further decline to about $10 \mathrm{~mm} \mathrm{Hg}$ within 30 minutes.

In the India ink experiments, two observers were independently able to classify correctly each pancreas according to the pressure used. In those cats in which a pressure of $40 \mathrm{~mm} \mathrm{Hg}$ had been maintained, the pancreas was stained a dense black (Fig. 2a). The fascia overlying the pancreas was distended with clear fluid and the gland appeared oedematous. Microscopically there were large clumps of ink particles outside ducts and acini (Fig. 2b). Both microscopically and macroscopically the distribution of ink particles was very patchy. The ink appeared to leave the acini through intercellular clefts (Fig. 2c). In tests where the pressure had been $30 \mathrm{~mm} \mathrm{Hg}$, each pancreas was again obviously discolored, but to a lesser extent (Fig. 3a). Microscopic examination showed foci of India ink outside the ducts and acini but this was also less marked (Fig. 3b). In tests where a pressure of $20 \mathrm{~mm} \mathrm{Hg}$ had been used the appear- ances were again very different, with only a faint grey discoloration detectable macroscopically (Fig. 4a) and practically no ink seen outside the ducts or acini on microscopic examination (Fig. 4b).

\section{Discussion}

In the unanaesthetized dog, the maximum secretory pressure of the pancreas has been recorded at 40 to $80 \mathrm{~mm} \mathrm{Hg}$ (Dragstedt, Haymond, and Ellis, 1934; Elliot, Williams, and Zollinger, 1957). In this study, peak pressures of 45 to $48 \mathrm{~mm} \mathrm{Hg}$ were found in anaesthetized cats. It is likely that higher pressures would be obtained in conscious cats (Byrne and Boyd, 1963).

The tests using India ink show that even in a 15-minute period, the duct contents can largely escape into the interstitial tissues at pressures below the maximum secretory pressure of the pancreas. Escape of duct contents into the interstitium of the gland has been previously shown by Herring and Simpson (1909) using carmine gelatin as a marker and by Rich and Duff (1936) using India ink. The pressures used in their experiments are not known, but are presumed to have been high. Egdahl (1958) injected India ink at pressures of 20 to $40 \mathrm{~mm} \mathrm{Hg}$ and found ink particles between the acinar cells and in the interstitium of the gland. No attempt was made to correlate the severity of ink staining with the pressure used. In the experiments reported here, there was a close correlation between the pressure in the pancreatic duct and the amount of ink seen in the interstitial tissues. Escape of ink was only obvious at pressures of 30 and $40 \mathrm{~mm} \mathrm{Hg}$. If the detailed studies of Menguy, Hallenbeck. 


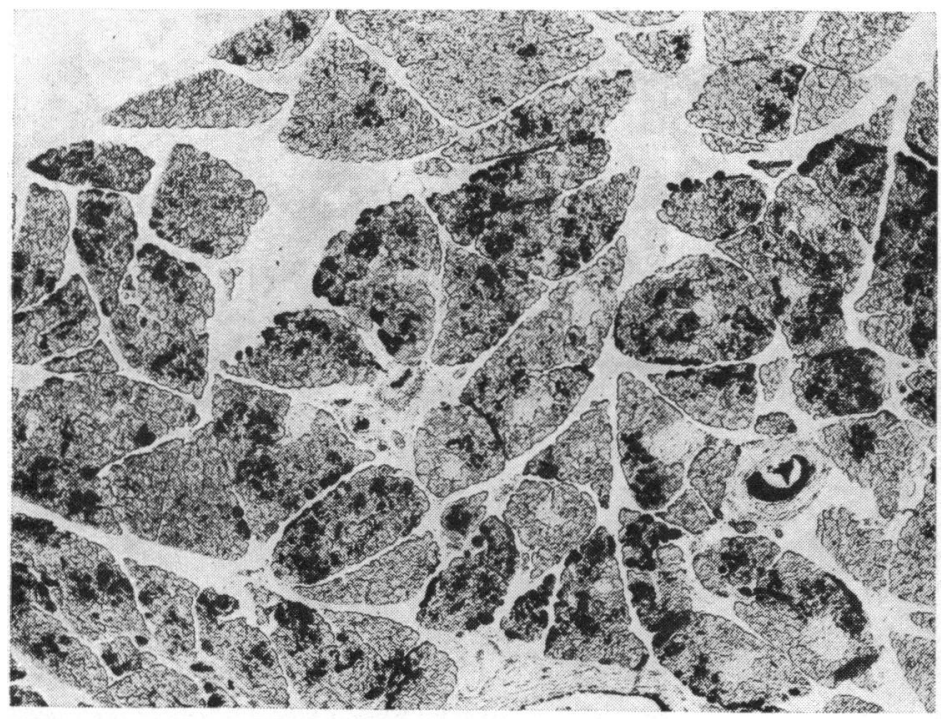

(2b)

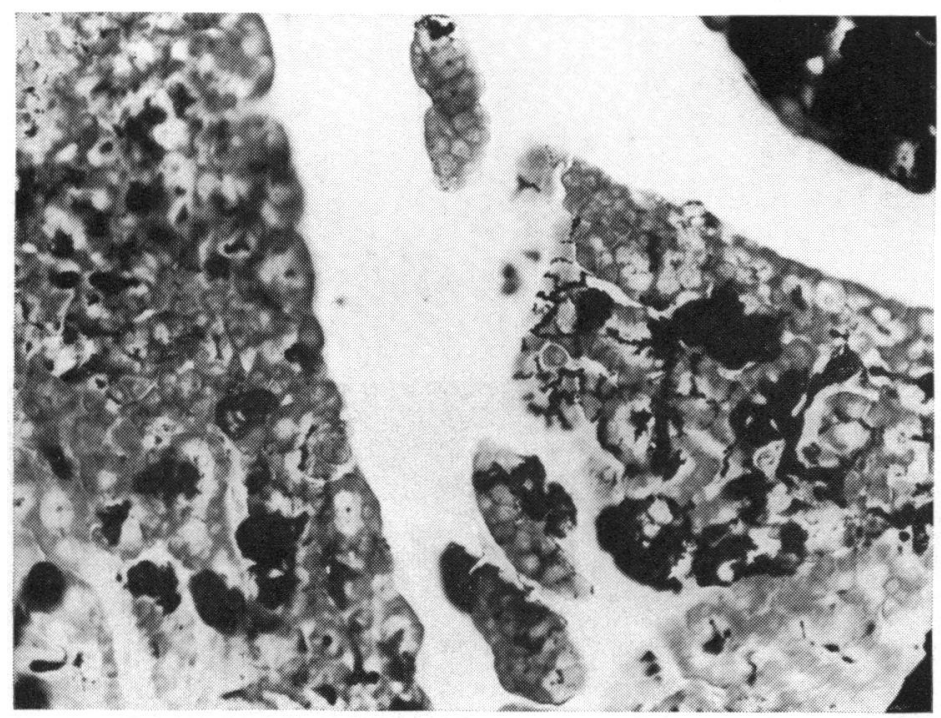

(2c)

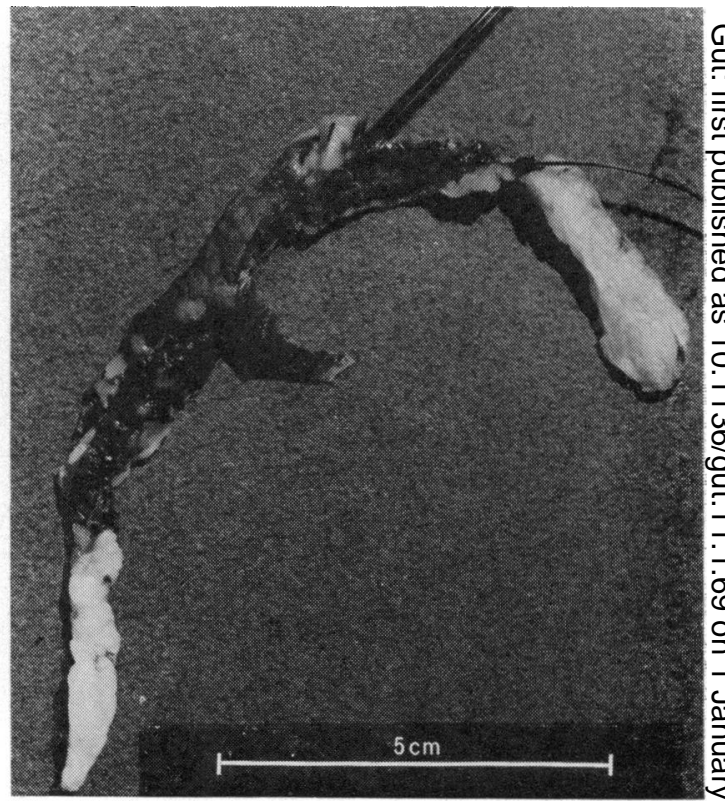

(2a)

Figs. $2 \mathrm{a}$ and $2 \mathrm{~b}$ The effect of raising the pressure in the pancreatic ducts to $40 \mathrm{~mm} \mathrm{Hg}$ for 15 minutes. The gland is stain?d a dense black. Microscopically large lumps of ink particles can be seen outside ducts and acini (neutral red $\times 63$ ).

Fig. 2c A higher magnification showing the ink appearing to leave the acini through intercellular clefts (neutral red $\times 160$ ).
Bollman, and Grindley (1958) in dogs can be applied to the cat, then the pancreatic duct pressure would be expected to be about $10 \mathrm{~mm}$ $\mathrm{Hg}$ and rarely to rise above $20 \mathrm{~mm} \mathrm{Hg}$. On the other hand, in the presence of combined obstruction and secretion, much higher pressures might be anticipated.

There is disagreement regarding the site of escape of pancreatic secretions during episodes of high pressure. Some authors claim that ducts rupture (Dreiling, Richman, and Fradkin, 1952; White, 1966). However, there is no published evidence to show that this occurs at physiological pressures. On the other hand, in this study and in that of Egdahl (1958), India ink was seen in clefts between the acini after pressures of less than $40 \mathrm{~mm} \mathrm{Hg}$ had been employed. Edlund, Ekholm, and Zelander (1963) have reported electron microscopic evidence of fine channels between acinar cells which would permit movement of fluid from the acini to the periacinar spaces.

Apart from pressure, other factors can affect the integrity of the duct-acinar system. The presence of pancreatitis itself will facilitate the passage of duct contents into the interstitial tissues. Thus, placing a radioopaque solution into the pancreatic ducts of man normally outlines only the ducts, whereas in the presence of acute inflammation, the whole gland becomes opacified (Doubilet, 1957). The nature of the duct contents is also important. Elliott et al (1957) found that 


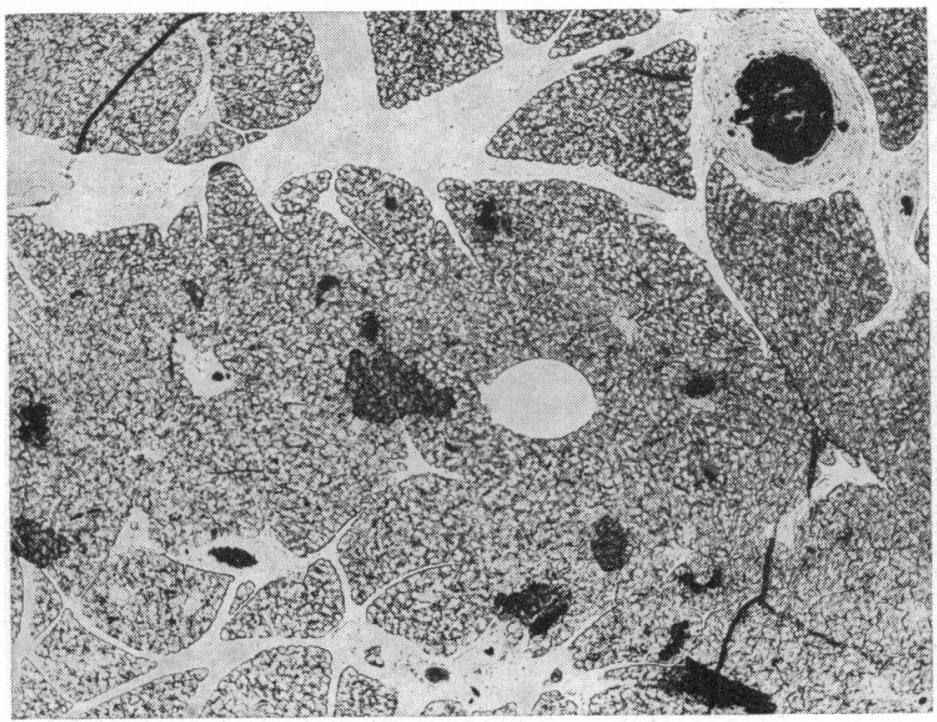

(3b)

Fig. 3a and $3 b \quad$ Effect of raising the pressure in the pancreatic ducts to $30 \mathrm{~mm} \mathrm{Hg}$ for 15 minutes.

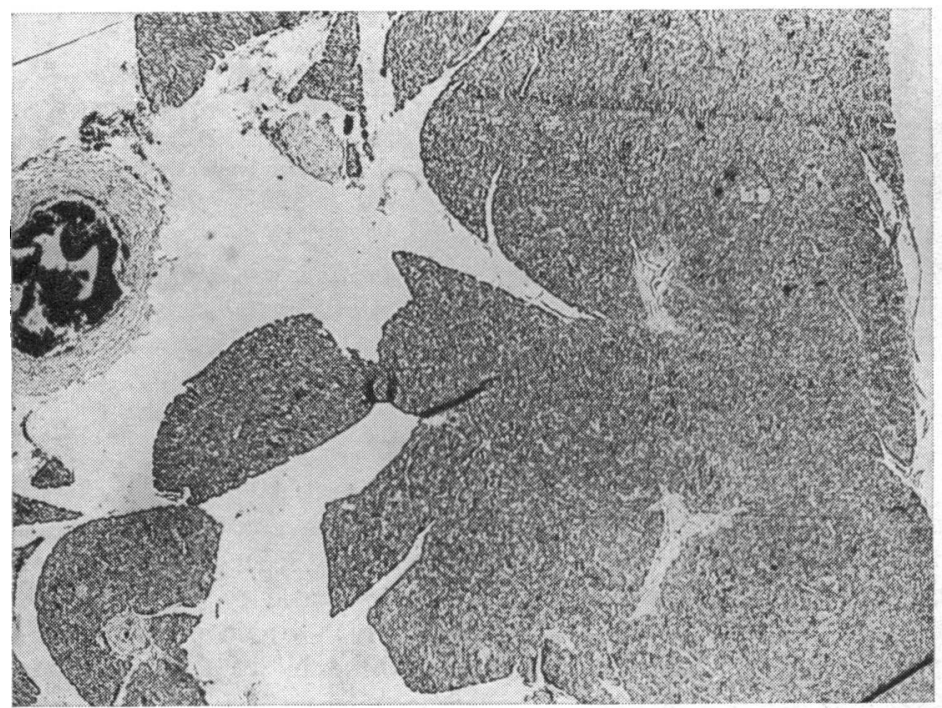

(4b)

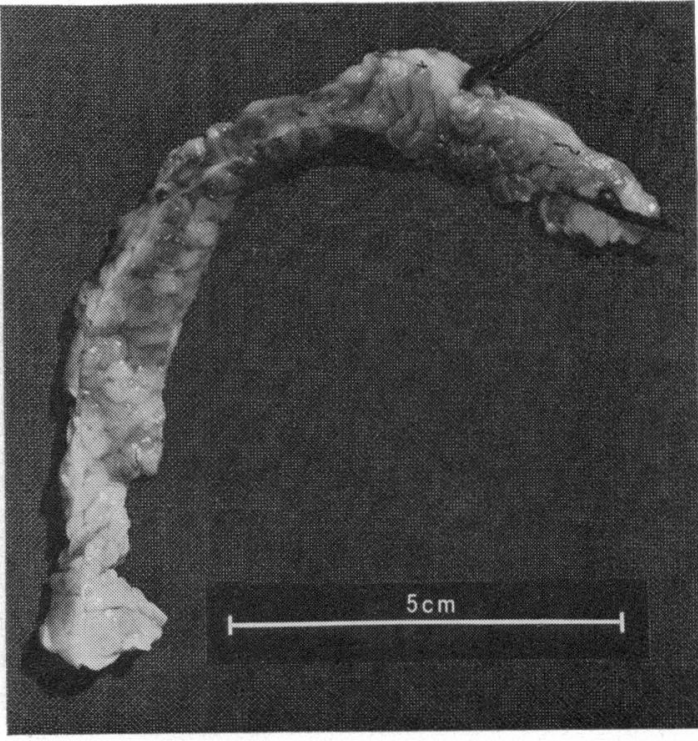

(3a)

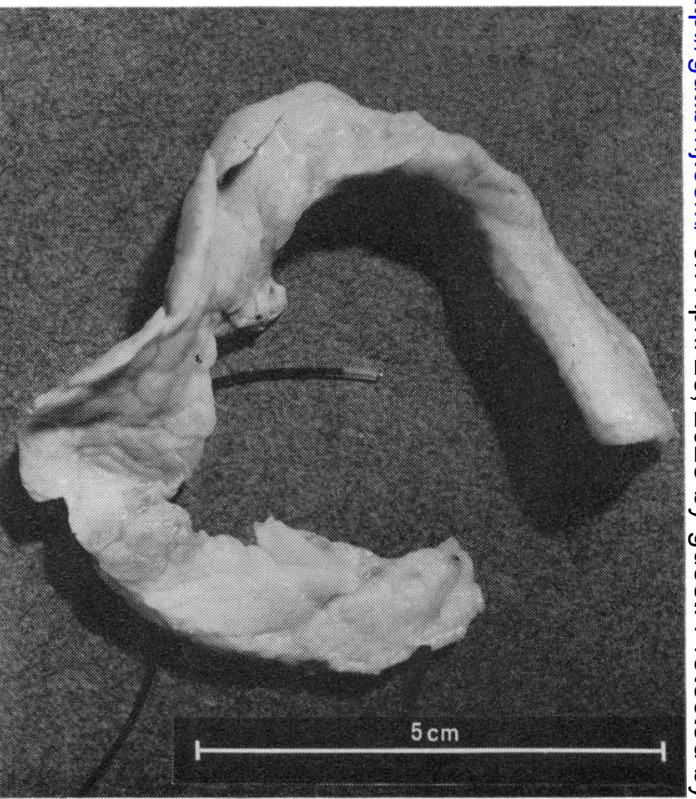

(4a)

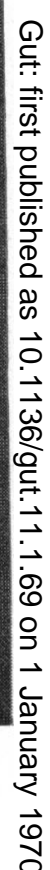

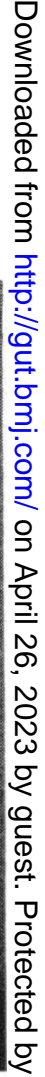

윰.

Figs. $4 \mathrm{a}$ and $4 \mathrm{~b}$ Effect of raising the pressure in the pancreatic ducts to $20 \mathrm{~mm} \mathrm{Hg}$ for 15 minutes. 
the pancreatic ducts of dogs were more permeable to a bile-trypsin mixture after it had been incubated than they were before incubation. These results have been confirmed by Joyeuse, Hallenbeck, and McCaughey (1962) and by McHardy, Craighead, Balant, Cradic, and La Grange (1963).

Thus, a rise in pressure, of no consequence in some circumstances, might be associated with extensive extravasation of duct contents in other circumstances.

This work was carried out with the help of a research grant from The National Health and Medical Research Council of Australia.

References

Bockus, H. L. (1965). Acute pancreatitis. In Gastroenterology, 2nd ed., Vol. 3, pp. 952-953. Saunders, Philadelphia and London.

Byrne, J. J., and Boyd, T. F. (1963). Hyperamylsemia in intestinal obstruction and its relationship to pancreatitis. Amer. $J$. Surg., 105, 720-729.

Doubilet, H. (1957). Discussion on chronic relapsing pancreatitis: physiological basis of treatment of pancreatitis. Proc. roy. Soc. Med., 50, 629-635.

Dragstedt, L. R., Haymond, H. E., and Ellis, J. C. (1934). Pathogenesis of acute pancreatitis (Acute pancreatic necrosis). Arch. Surg., 28, 232-291.

Dreiling, D. A., Richman, A., and Fradkin, N. F. (1952). The role of alcohol in the etiology of pancreatitis: a study of the effect of intravenous ethyl alcohol on the external secretion of the pancreas. Gastroenterology, 20, 636-646.

Edlund, Y., Ekholm, R., and Zelander, T. (1963). The effect of intraductal pressure increase on the ultrastructure of the pancreas. Acta chir. scand., 125, 529-530.

Egdahl, R. H. (1958). Mechanism of blood enzyme changes following the production of experimental pancreatitis. Ann. Surg., 148, 389-399.

Elliott, D. W., Williams, R. D., and Zollinger, R. M. (1957). Alterations in the pancreatic resistance to bile in the pathogenesis of acute pancreatitis. Ann. Surg., 146, 669-682.
Herring, P. T., and Simpson, S. (1909). The pressure of pancreatic secretion and the mode of absorption of pancreatic juice after obstruction of the main ducts of the pancreas. Quart. J. exp: Physiol., 2, 99-108.

Joyeuse, R., Hallenbeck, G. A., and McCaughey, W. T. E. (1962). Experimental production of pancreatitis by infusion of mixtures of bile and pancreatic juice into the pancreatic duct. Ann. Surg., 156, 74-80.

McHardy, G., Craighead, C. C., Balant, L., Cradic, H., and La Grange, C. (1963). Pancreatitis-intrapancreatic proteolytic trypsin activity. J. Amer. med. Ass., 183, 527-529.

Menguy, R. B., Hallenbeck, G. A., Bollman, J. L., and Grindlay, J. H. (1958).Intraductal pressures and sphincteric resistance in canine pancreatic and biliary ducts after various stimuli. Surg. Gynec. Obstet., 106, 306-320.

Rich, A. R., and Duff, G. L. (1936). Experimental and pathological studies on the pathogenesis of acute hemorrhagic pancreatitis. Bull. Johns Hopkins Hosp., 58, 212-258.

Snodgrass, P. J., and Ingelfinger, F. J. (1966). Disorders of the pancreas. In Principles of Internal Medicine. 5th ed., p. 1098. Edited by T. R. Harrison, R. D. Adams, I. L. Bennett, W. H. Resnik, G. W. Thorn, and M. M. Wintrobe. McGraw-Hill, New York.

White, T. T. (1966). Pancreatitis. Arnold, London. 